\title{
Outcome of Teenage Pregnancy in a Low Resource Setting: A Comparative Study
}

\section{Augustine Adebayo Adeniyi ${ }^{*}$, Adebimpe Oyinloye², Babatunde Sunday Awoyinka1, Olabisi Timothy Adeyemoํㅜ , Olumide Mojisola Ayankunle ${ }^{1}$}

\author{
${ }^{1}$ Department of Obstetrics and Gynaecology, Afe Babalola University, Ado Ekiti, Nigeria \\ ${ }^{2}$ Department of Obstetrics and Gynaecology, Federal Teaching Hospital, Ido Ekiti, Nigeria \\ Email: *adeniyiaa@abuad.edu.ng
}

How to cite this paper: Adeniyi, A.A., Oyinloye, A., Awoyinka, B.S., Adeyemo, O.T. and Ayankunle, O.M. (2021) Outcome of Teenage Pregnancy in a Low Resource Setting: A Comparative Study. Open Journal of Obstetrics and Gynecology, 11, 504-515. https://doi.org/10.4236/ojog.2021.115047

Received: March 11, 2021

Accepted: May 10, 2021

Published: May 13, 2021

Copyright $\odot 2021$ by author(s) and Scientific Research Publishing Inc. This work is licensed under the Creative Commons Attribution International License (CC BY 4.0).

http://creativecommons.org/licenses/by/4.0/

\begin{abstract}
Background: Teenage pregnancy constitutes a high-risk pregnancy due to possible physical, psychological, socio-economic and increased obstetric risks associated with it. These risks though equally present in the older pregnant women are probably less when compared with teenagers. Thus perinatal outcome of pregnancies in these groups of patients varies. Objective: To compare the socio-demographic characteristics, pattern of pregnancy complications and perinatal outcome of pregnancy among primigravid teenagers and older primigravid women. Method: A comparative study was carried out among 58 primigravid teenagers and equal numbers of adult primigravidae at Federal Teaching Hospital, Ido Ekiti, Nigeria over five year period between January 2008 and December, 2012. Their socio-demographic characteristics, booking status, pregnancy complications, estimated gestational age at delivery, mode of delivery, post-partum morbidities, neonatal birth weight and perinatal mortalities were obtained from their case notes. Results: Deliveries by teenagers accounted for $2.48 \%$ of all deliveries during the period under review. Teenage age was significantly associated with unmarried status $(\mathrm{P}<$ 0.001). Two-third (67.2\%) of the teenagers were unbooked for antenatal care whereas less than one-quarter of the adult were unbooked. Pregnancy related complications such as, hypertensive disorders of pregnancy, cephalopelvic disproportion/obstructed labour and anaemia were more among the teenagers compared with the older women. There were also more preterm deliveries among the teenagers compared with the older women (17.2\% VS 5.2\%). Perinatal mortality rate was $155 / 1000$ birth among the teenagers. The incidence of Low birth weight and perinatal mortality were significantly higher among the teenage mothers $(\mathrm{P}<0.05)$. However, there was no statistical difference in the occurrence of morbidity and maternal mortality in both groups $(\mathrm{P}>$ 0.05). Conclusion: Pregnancy and deliveries in teenagers are high risk.
\end{abstract}


Therefore, sex education as well as access to reproductive health information and care will help reduce the occurrence of unwanted pregnancies and their lasting impact on teenagers, their families, and the society.

\section{Keywords}

Teenage Pregnancies, Obstetric Complications, Outcome

\section{Introduction}

Teenage period is defined as the age bracket between thirteen and nineteen (1319) years [1]. It is a period of sexual maturity, psychological, and emotional development from those of a child to those of an adult. It also represents a transition from the state of socio-economic dependence to one of relative independence [2]. Teenage pregnancy constitutes both biological risk as well as a psychosocial and economic problem. Teenage mothers are young girls who are still growing and they are ill-equipped physiologically, socio-economically, culturally and even psychologically to cope with pregnancy [3] [4]. Teenage pregnancy continues to be a challenging issue for families, health workers, educators, society, government, and the teenagers themselves [5] [6]. This age group constitutes about 1.5 billion persons out of a total human population. Eighty-six percent of this sub-group live in the developing countries [7]. Teenage pregnancy constitutes about 13 million pregnancies every year in the world, accounting for $10 \%$ of all births worldwide [8]. More than $90 \%$ of these are in the developing countries [9]. The highest rate of teenage pregnancy in the world is in Sub Saharan Africa where women tend to marry at an early age. In West Africa, about $55 \%$ of women are said to give birth by 20 years of age. This translates to about 143 births/1000 teenagers as against the world figure of 65/1000 teenagers [9] [10] [11] and 2.9/1000 in South Korea.

In Nigeria, the estimated pregnancy rate by the National Demographic Health Survey in 2006 was $22 \%$. However, the incidence varies in different parts of Nigeria. From Bayelsa, Awka, Ilorin and Sokoto, incidence of teenage deliveries were $6.2 \%, 1.67 \%, 9.93 \%$ and $11.8 \%$ of all deliveries in their tertiary health institutions respectively [3] [12] [13] [14] [15]. The problems of teenage pregnancy have been attributed to various predisposing factors. One major factor is early coitarche which is as a result of early sexual maturation with decreasing age at menarche. Adolescents become sexually mature and fertile approximately 4 - 5 years before they reach emotional maturity [16].

Others are increased public media emphasis on sexual activity, increased cultural permissiveness to sex, peer pressure, lack of parental guidance, lack of nurturing and attentive parents, being raised by single parents as well as a history of sexual abuse [15] [16].

Pregnancy in teens poses an extra nutritional need and as well put them at a socio-economic disadvantage, especially in developing countries. These predis- 
pose them to complications especially at the antenatal and intra-partum period. Among these include: unsafe abortion, pregnancy-induced hypertension, nutritional anaemia in pregnancy, malaria in pregnancy, preterm labour, low birth weight babies, higher risk of having babies with birth defect, poor maternal weight gain, sexually transmitted infections, feto-pelvic disproportion, increased obstetric intervention all culminating in increased maternal, peri-natal and neonatal morbidity and mortality [3] [15] [17] [18] [19] [20]. This study was designed to compare the outcome of teenage pregnancy in Tertiary hospital in Southwest Nigeria.

\section{Materials and Methods}

A retrospective cross sectional study was conducted at Federal Teaching Hospital, Ido Ekiti, Nigeria over 5 years. All primigravidae parturients whose ages were less than 20years and whose pregnancies were 28weeks and above, and those who delivered at study Centre between $1^{\text {st }}$ Jan 2008 and $31^{\text {st }}$ December 2012 were included. A comparison was made with primigravidae adult mothers aged 20 34 years selected from the first women in the birth registry who delivered after each study case and satisfied the inclusion criteria as control. As the control group, women aged between 20 - 34 years were considered since this age-group is generally regarded as safe for childbirth. Women with pre-existing medical problems and women aged $>35$ years and those who have had 2 parous experiences and above were excluded. Case notes of 116 parturients (comprising the 58 cases and 58 controls) were retrieved from the Health Records Department and relevant data extracted using proforma. Information obtained included the age of the parturient, marital status, educational status, occupation, booking status, pregnancy complications, estimated gestational age at delivery, mode of delivery, post-partum morbidities, neonatal birth weight and perinatal mortalites. Anaemia was defined as packed cell volume of less than $30 \%$ at any stage of pregnancy. Hypertension was present when 2 blood pressure readings of $140 \mathrm{mmHg}$ systolic and $90 \mathrm{mmHg}$ diastolic or above were recorded at least 6 hours apart. Patients who were first seen in labour are regarded as unbooked whether they are referred from another medical unit or not. Birthweight below $2.5 \mathrm{~kg}$ was defined as low birthweight and deliveries before 37 completed weeks of gestation were classified as preterm.

These data were analysed using SPSS version 16 . The mean and percentages were used to describe the quantitative data. The chi-square and student t-test were used to test for statistical significance. A P value of less than 0.05 was taken as significant.

\section{Results}

During the period under review, a total of 58 teenage mothers delivered in our facility out of a total of 2350 deliveries conducted. Delivery by teenagers accounted for $2.48 \%$ of all deliveries. The obstetric outcome of teenagers was 
compared with older women aged 20 - 34 years. The mean age in the teenage group was $17.8 \pm 1.3$ years (ranges $14-19$ year) and the mean age in the older women was $27.4 \pm 3.4$ years. Nine $(15.5 \%)$ of teenagers belonged to younger teenage group of 16 years or less and the youngest girl in the study was 14 years at delivery.

The different socio-demographic characteristics are summarized in Table 1. Among the teenagers, 48 (82.8\% VS 8.6\%) were unmarried while most $(91.4 \%$ VS $17.2 \%)$ of the older women were married. Teenage age was significantly associated with unmarried status $(\mathrm{P}<0.001)$. Two-third $(67.2 \%)$ of the teenagers were unbooked for antenatal care, compared with the older women among whom less than one-quarter $(24.1 \%)$ were unbooked and majority of them booked pregnancy for antenatal care. Teenage age was significantly associated with unbooked status. Only $28(48.2 \%)$ of the teenagers had completed education (secondary and tertiary) while 54 (93.1\%) of the older women had at least completed secondary school education (secondary and tertiary education).

Figure 1 showed that only 5 (8.6\%) of the teenagers earn a form of income while the older age group has a higher proportion $(44 ; 75.9 \%)$ of women who are income earners. There is a significant association between teenage pregnancy and unemployment $\left(\mathrm{X}^{2}=53.74 ; \mathrm{P}<0.001\right)$.

Pregnancy related complication was significantly higher among teenagers than the older women $\left(\mathrm{X}^{2}=9.992 ; \mathrm{P}=0.002\right)$ and there is a significant association between unbooked status and occurrence of complication among the teenage mothers $(\mathrm{P}$ value $=0.016)$.

Table 1. Comparison of teenage and older mothers according to different socio-demographic characteristics.

\begin{tabular}{|c|c|c|c|c|c|c|}
\hline & \multicolumn{2}{|c|}{ Teenager $(n=58)$} & \multicolumn{2}{|c|}{ Control $(n=58)$} & \multirow[b]{2}{*}{$\mathrm{X}^{2}$} & \multirow[b]{2}{*}{ P-value } \\
\hline & No & $\%$ & No & $\%$ & & \\
\hline \multicolumn{7}{|l|}{ Marital Status } \\
\hline Unmarried & 48 & 82.8 & 5 & 8.6 & 64.2 & $<0.001$ \\
\hline Married & 10 & 17.2 & 53 & 91.4 & & \\
\hline \multicolumn{7}{|l|}{ Booking status } \\
\hline Unbooked & 39 & 67.2 & 14 & 24.1 & 21.7 & $<0.001$ \\
\hline Booked & 19 & 32.8 & 44 & 75.9 & & \\
\hline \multicolumn{7}{|l|}{ Educational status } \\
\hline No formal education & 1 & 1.7 & 0 & 0.0 & & \\
\hline Primary education only & 0 & 0.0 & 0 & 0.0 & & \\
\hline Uncompleted secondary education & 29 & 50.0 & 4 & 6.9 & & \\
\hline Completed secondary education & 22 & 37.9 & 16 & 27.6 & & \\
\hline Tertiary education & 6 & 10.3 & 38 & 65.5 & & \\
\hline Total secondary and Tertiary Education & 28 & 48.2 & 54 & 93.1 & & \\
\hline
\end{tabular}




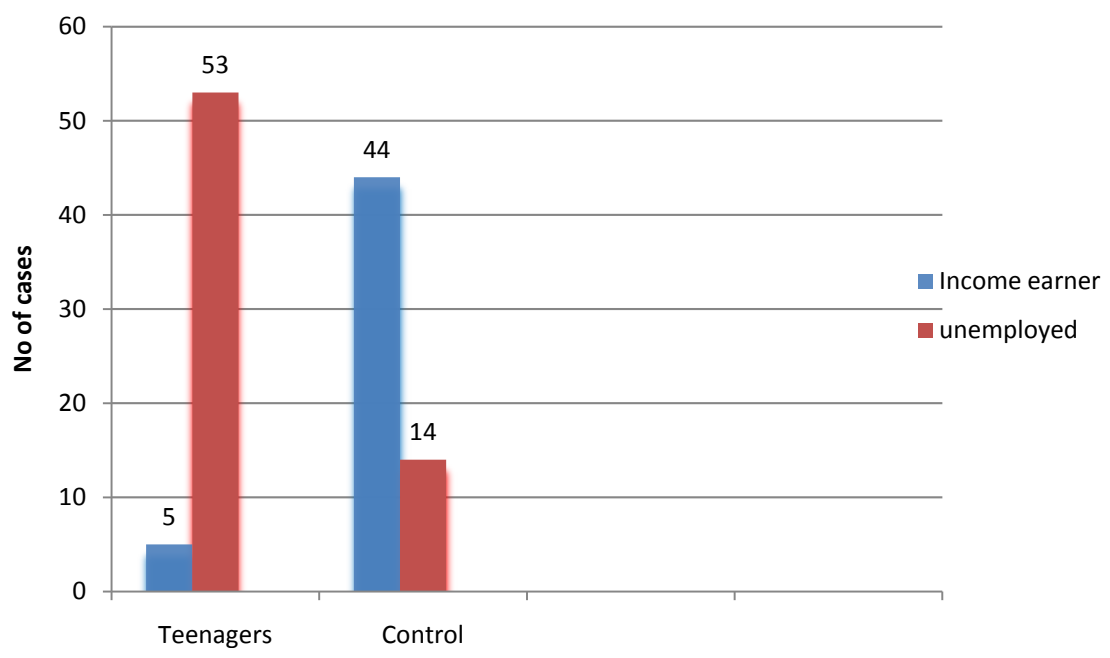

Figure 1. Comparison of the socio-economic status of the teenagers and the control.

Table 2, showed the various complications as they occur in both groups. Hypertensive disorders of pregnancy, cephalopelvic disproportion/obstructed labour and anaemia were the commonest complication among the teenagers $(\mathrm{P}>0.05)$.

Table 3, showed that there were more preterm deliveries among the teenagers when compared with the older women (17.2\% VS 5.2\%). However, there was no significant difference in the incidence of preterm delivery between the two groups $(\mathrm{P}>0.005)$. The mean gestational age at delivery for the teenagers was $37.9 \pm 2.4$ weeks while that of the older women was $39.0 \pm 1.7$ weeks which was statistically significant $(\mathrm{t}=-2.559, \mathrm{P}=0.014)$. Thirty-six $(62.1 \%)$ of the teenagers had spontaneous vaginal delivery while $43(74.1 \%)$ of the older women had spontaneous vaginal delivery. The difference was not statistically significant $(P>0.005)$. The incidence of vacuum delivery was similar in both groups. There were a total of 21 cases of caesarean deliveries among the teenagers and all were emergency caesarean sections giving a caesarean section rate of $36.2 \%$. Among the older women $14(24.1 \%)$ had caesarean section out of which 10 (17.2\%) were emergency and 4 (6.9\%) elective. The difference in the caesarean section rate was not statistically significant $(\mathrm{P}>0.005)$. The indication for caesarean section was similar in both groups. The commonest indication was cephalopelvic disproportion/obstructed labour and severe preeclampsia/eclampsia. Eight (13.8\%) of the teenagers had post-partum morbidities which included post-partum hemorrhage, anaemia requiring blood transfusion, wound sepsis, paraparesis and acute kidney injury while only 3 (5.2\%) of the older women had morbidities; 2 postpartum hemorrhages and 1 wound sepsis. There was no statistical difference in the occurrence of morbidity in both groups. There was also no maternal mortality among the studied population.

Table 4, compared the perinatal outcome of delivery of both group. There were $9(15.5 \%)$ perinatal mortalities among the neonates born to teenage mothers and $1(1.7 \%)$ perinatal mortality recorded among the older women giving a perinatal mortality rate of $155 / 1000$ births in infants of teenage mothers. The 
Table 2. Shows the pregnancy complications in both groups.

\begin{tabular}{ccccccr}
\hline & \multicolumn{2}{c}{ Teenager $(\mathrm{n}=58)$} & \multicolumn{2}{c}{ Control $(\mathrm{n}=58)$} & $\mathrm{X}^{2}$ & P-value \\
\hline Complication & No & $\%$ & No & $\%$ & & \\
None & 22 & 37.9 & 39 & 67.2 & & \\
Malaria & 3 & 5.2 & 3 & 5.2 & & \\
Anaemia & 5 & 8.6 & 0 & 0.0 & & \multirow{2}{*}{0.002} \\
Antepartum hemorrhage & 3 & 5.2 & 3 & 5.2 & \\
Urinary tract infection & 1 & 1.7 & 2 & 3.4 & \\
Premature rupture of membrane & 5 & 8.6 & 2 & 3.4 & \\
Pre-eclampsia/Eclampsia & 8 & 13.8 & 5 & 8.6 & \\
Cephalopelvic disproportion/ & 8 & 13.8 & 5 & 5.2 & \\
Obstructed labour & 1 & 1.7 & 1 & 1.7 & \\
$\quad$ Cord prolapsed & 2 & 3.4 & 1 & 1.7 & \\
Severe oligohydramnios & & & & & \\
\hline
\end{tabular}

Table 3. Shows the intrapartum and the post-partum events in both groups.

\begin{tabular}{ccccccc}
\hline & \multicolumn{2}{c}{ Teenager $(\mathrm{n}=58)$} & Control $(\mathrm{n}=58)$ & $\mathrm{X}^{2}$ & P-value \\
\cline { 2 - 6 } & No & $\%$ & No & $\%$ & & \\
\hline Period of gestation at delivery & & & & & & \\
Preterm & 10 & 17.2 & 3 & 5.2 & 4.245 & 0.074 \\
Term & 39 & 67.2 & 52 & 89.7 & & \\
Unsure & 9 & 15.5 & 3 & 5.2 & & \\
Mode of delivery & & & & & & \\
Vaginal & 36 & 62.1 & 43 & 74.1 & 1.945 & 0.163 \\
Vacuum & 1 & 1.7 & 1 & 1.7 & & \\
Emergency LSCS & 21 & 36.2 & 10 & 17.2 & \multirow{2}{*}{0.157} \\
Elective LSCS & 0 & 0.0 & 4 & 6.9 & & \\
Post-partum morbidities & & & & & & \\
None & 50 & 86.2 & 55 & 94.8 & & \\
Post-partum hemorrhage & 1 & 1.7 & 2 & 3.4 & & \\
Paraparesis & 1 & 1.7 & 0 & 0.0 & & \\
Anaemia & 2 & 3.4 & 0 & 0.0 & 2.511 & 0.204 \\
Wound sepsis & 3 & 5.2 & 1 & 1.7 & & \\
Acute kidney injury & 1 & 1.7 & 0 & 0.0 & & \\
\hline
\end{tabular}

Table 4. Shows the perinatal outcome of both groups.

\begin{tabular}{cccccccc}
\hline & \multicolumn{2}{c}{ Teenager $(\mathrm{n}=58)$} & \multicolumn{2}{c}{ Control $(\mathrm{n}=58)$} & \multirow{2}{*}{$\mathrm{X}^{2}$} & \multirow{2}{*}{ P value } \\
& No & $\%$ & No & $\%$ & & \\
\hline Perinatal mortality & 9 & 15.5 & 1 & 1.7 & 7.004 & 0.016 \\
\hline
\end{tabular}


Continued

\begin{tabular}{ccccccc}
\hline Alive & 49 & 84.5 & 57 & 98.3 & & \\
Birth-weight & & & & & & \\
Low birth-weight & 20 & 34.5 & 5 & 8.6 & 11.473 & 0.001 \\
$\begin{array}{c}\text { Average birth-weight and above } \\
\text { Congenital abnormality }\end{array}$ & 38 & 65.5 & 53 & 91.4 & & \\
None & 56 & 96.6 & 58 & 100.0 & & \\
Anencephaly & 1 & 1.7 & 0 & 0.0 & 2.035 & 0.496 \\
Multiple anomaly & 1 & 1.7 & 0 & 0.0 & & \\
\hline
\end{tabular}

difference in the incidence of perinatal mortality between the two groups of patients was found to be statistically significant $(\mathrm{p}=0.016)$. Twenty $(34.5 \%)$ of the infants of the teenagers weighed less than $2.5 \mathrm{~kg}$ while the corresponding figure for the older women was $5(8.6 \%)$ the difference was statistically significant $(\mathrm{p}=$ 0.001 ). The mean birth weight in the teenage group was $2.72 \mathrm{Kg} \pm 0.69 \mathrm{Kg}$ and $3.08 \mathrm{Kg} \pm 0.55 \mathrm{Kg}$ in the older women. The difference was also significant $(\mathrm{P}=$ 0.001). There were 2 cases of delivery of infants with congenital abnormality among the teenage mothers while there was no similar occurrence among the older women

\section{Discussion}

Teenage pregnancy constitutes about 13 million pregnancies every year in the world, accounting for $10 \%$ of all births worldwide [8]. The incidence of teenage pregnancy in this study was $2.48 \%$ which is higher than the incidence of $1.67 \%$ found in Enugu, but lower than the incidence of 13.1\% reported in Ilorin [3] [14]. Nine (15.5\%) of teenagers in this study belongs to younger teenage age of 16 years and less. This disparity within the same country is believed to be mainly due to differences in the socio-cultural and religious practices such as early marriage which is prevalent in the Northern States of Nigeria where Islam is the predominant religion [3] [21] [22].

Similar to studies done at Enugu and Niger-Delta [13] [14], majority of teenagers in this study were unmarried, had less than completed secondary school education, and were unemployed. These findings in a way reflected their socio-economic status as they constituted a disadvantaged group. Studies have shown that most young mothers are disadvantaged educationally, economically, and socially compared with those who delay childbearing until their $20 \mathrm{~s}$ [8] [23] [24]. Probably the most damaging consequence of teenage motherhood is the disruption of schooling. Early childbearing has a greater detrimental effect on educational attainment than social background, ethnicity, parents' socioeconomic status or academic aptitude or expectations [23] [24]. One such study found that giving birth while in one's teens leads to a $50 \%$ reduction in the likelihood of high school completion compared with not giving birth in one's teens 
[25]. These under-educated and most often, single teens face a future of dependency and/or underemployment. Two-thirds of the teenage mothers in this study did not have adequate antenatal care similar to the finding in many other studies [3] [10]. Yildirim Y reported 77\% of teenage mothers had not been followed up by an obstetrician [26]. The inadequate antenatal care in this study might be because the teenage mothers are reluctant to seek medical advice or related to pregnancy denial or as a result of their low socio-economic status, lack of psychological and financial support. This indicates that the teenage mothers were less careful about their pregnancy probably because of the lack of awareness and maturity. This may account for the higher incidence of pregnancy related complications observed amidst this group of mothers. Anaemia was most common in young age group (8.6\% VS $0.0 \%$ ). Moini A found anaemia to be a common complication in teenagers [27]. This might have been caused by poorer nutrition and low income. Teenage mothers are more likely to be in worse nutritional conditions before conception than older women, and the effect of poor prepregnancy nutrition is exacerbated by increased nutritional demand placed on them by the growing fetus [28]. Pre-eclampsia often severe and eclampsia has been a common problem teenage pregnancy [29] [30]. The incidence in this study is higher than in the control group. This result is in agreement with the report by Aboyeji A.P but in contrast to that reported by Osbourne [29]. Preeclampsia often complicates pregnancy in women at the extremes of the reproductive age. Teenage mothers are children at stage of rapid growth and whose pelvic bone could be underdeveloped as at when pregnancy occurred, hence the higher incidence of celphalopelvic disproportion/obstructed labour observed in them in this study despite a relatively lower birth-weight of infant delivered to the teenage mothers. Other complications observed in this study have a similar incidence among the two groups of patients.

Higher incidence of caesarean deliveries was observed among the teenage group compared to the older mothers in this study. This is due to the fact that most of the teenagers in this study were unbooked and presented with complications necessitating operative delivery. Other studies had observed a higher proportion of normal delivery among teenage mothers compared to the older mothers, which could be due to the fact that more of the teenagers in those studies had antenatal care thus reducing the incidence of pregnancy related complications observed in those studies [4] [30] [31]. The teenage mothers had a significantly higher number of preterm deliveries compared to the adult mothers in this study. Such a high incidence of preterm labour and delivery lead to higher risks for the neonate. Many authors have reported an association between teenage pregnancy and preterm delivery [22] [27]-[32]. There is higher frequency of occurrence of low birthweight babies in the teenage-group than controls. Low birthweight is a key predictor of malnutrition and an important determinant of child mortality [33]. One of the most detrimental outcomes of low birthweight is growth retardation, and if the newborn happens to be a girl, it perpetuates a vi- 
cious cycle of female malnutrition throughout adolescence and adulthood. This process gives rise to a condition of intergenerational transmission of physical (small mothers have small babies), social and economic disadvantages into the next generation [34]. This study found that the number of low-birthweight babies was more in the case of teenage mothers (34.5\%) compared to the older mothers (8.9\%). Prianka et al. in a study done in India also found a higher incidence of low birth weight babies among the teenagers compared to the adult mothers (38.9\% VS 30.4\%) [32]. The low socio-economic status of the teenagers in this study predisposes them not only to pregnancy related complications but also to increased post-partum morbidities. This may be because teenagers are more likely to experience neglected complication in pregnancy such as eclampsia, prolonged obstructed labour which could predispose them to post-partum hemorrhage, anaemia, acute kidney injury from hypovolemia and even paraparesis as was observed in this study. Post-partum care in teenagers especially related to use of antibiotics also is hindered by unfavorable financial situation, thus leading to complications such as wound sepsis. These complications are less common among the older women because of their better financial status. Fifteen percent perinatal mortality was observed among the teenage group in this study and it is significantly higher than what was observed among the neonate of older women (1.7\%). This is as a result of the inadequate antenatal care observed in the teenage group, the higher rate of complications and the high possibility of neglected prolonged labour before presentation to our facility. Prianka Mukhopadhyay et al. also observed a significantly higher incidence of perinatal death among infants of teenage mothers in India. Iklaki C.U. et al. found a significantly high incidence of still-birth (29.0\%) among unbooked teenage mothers in Calabar further stressing the effect of inadequate antenatal care on adverse perinatal outcome of teenage pregnancy [35]. The congenital abnormalities observed among neonate of teenage mothers in this study also contributed to the perinatal mortality. The perinatal mortality rate among teenagers in this study is $155 / 1000$ birth. There was no maternal mortality among the teenagers throughout the studied period. It is worthy of note however that only a fraction of the affected teenagers get to a health care facility like ours for management and majority of them never get the opportunity. Thus, the problem of teenage pregnancy is much more prevalent than the observation in this study. In an environment like ours where high level of illiteracy, poverty and inadequate medical facilities are common, pregnancy and deliveries in teenagers are unsafe. Sex education as well as access to reproductive health information and care will help reduce the occurrence of unwanted pregnancies and their lasting impact on teenagers, their families, and the society. In situations where pregnancy has occurred, provision of comprehensive social, educational and health services for this group will help to prevent and or give room for early detection of pregnancy complication, thus ensuring safe motherhood. Improvement in the socio-economic status of the teenager will also create a favourable condition for child bearing. 
The findings of this study are however limited by the sample size and being a hospital based study, a population based study will improve on the findings.

\section{Conflicts of Interest}

The authors declare no conflicts of interest regarding the publication of this paper.

\section{References}

[1] (2003) McGraw-Hill Concise Dictionary on Modern Medicine. http://medicaldictionary.Thefreedictionary.com/teenagepregnancy

[2] WHO (1988) Report of a WHO Meeting on Adolescent Sexual and Reproductive Health. Educational and Service Aspect. Mexico City 28th April-2nd May 1988.

[3] Jimoh, A.S. and Abdul, I.F. (2004) Outcome of Teenage Pregnancies in Ilorin, Nigeria. Tropical Journal of Obstetrics and Gynaecology, 21, 27-31. https://doi.org/10.4314/tjog.v21i1.14459

[4] Trividi, S.S. and Pasrija, S. (2007) Teenage Pregnancies and Their Obstetrics Outcomes. Tropical Doctor, 37, 85-88. https://doi.org/10.1177/004947550703700208

[5] Carter, D.M., Felice, M.E., Rosoff, J., Zabin, L.S., Beilenson, P.L., et al. (1994) When Children Have Children: The Teenage Pregnancy Predicament. American Journal of Preventive Medicine, 10, 108-113. https://doi.org/10.1016/S0749-3797(18)30627-5

[6] Jaiskievicz, J.A. and Mc Arnarney, E.R. (1994) Pregnancy during Adolescence. Pediatric Review, 15, 32-38. https://doi.org/10.1542/pir.15-1-32

[7] UNFPA (2009) State of the World Population: Globalis. GRU. UNU. Educational Indicator. CFM.ID-127.

[8] Nili, F., Ralimati, M.R. and Sharifi, S.M. (2002) Maternal and Neonatal Outcome in Teenage Pregnancy in Tehran Valiasr Hospital. Acta Medica Iranica, 40, 55-59.

[9] Mayor, S. (2004) Pregnancy and Childbirth Are Leading Causes of Death in Teenage Girls in Developing Countries. BMJ, 328, 1152-1153. https://doi.org/10.1136/bmj.328.7449.1152-a

[10] Akande, O.E. (2009) In Craig C: Teenage Pregnancy under Spotlight.

[11] UNICEF (2001) A League Table of Teenage Births in Rich Nations.

[12] Federal Ministry of Health (2002) Nigerian Demographic and Health Indicator Framework and Planning, Abuja, 2002-2006.

[13] Ibrahim, I.A. and Owoeye, G. (2012) Outcome of Teenage Pregnancy in Niger Delta of Nigeria. Ethiopian Journal of Health Sciences, 22, 43-50.

[14] Ezegwui, H.U., Ikeako, L.C. and Ogbuefi, F. (2011) Obstetrics Outcome of Teenage Pregnancies at a Tertiary Hospital in Enugu, Nigeria. Nigerian Medical Journal, 52, 230-234.

[15] Nwoboro, E. and Adoke, K.U. (2005) Obstetrics Outcome of Teenage Pregnancies at a Tertiary Care Hospital in Sokoto, Nigeria. Tropical Journal of Obstetrics and Gynaecology, 22, 168-170. https://doi.org/10.4314/tjog.v22i2.14520

[16] Dangal, G. (2005) An Update on Teenage Pregnancy. The Internet Journal of Gynaecology and Obstetrics, 5, 3. https://doi.org/10.5580/9ff

[17] Allan Guttmacher Institute (2004) Early Child Bearing in Nigeria: A Continuing Challenge. Research in Brief, 2, 1-8. http://www.guttmatcher.org 
[18] Loto, O.M., Ezechi, O.C., Kalu, B.K., Loto, A., Ezechi, L. and Ogunniyi, S.O. (2004) Poor Obstetrics Performance of Teenagers: It Is Age or Quality of Card Related. Journal of Obstetrics and Gynaecology, 24, 398. https://doi.org/10.1080/01443610410001685529

[19] United Nations (1995) The World's Women, 1995: Trends and Statistics. United Nations, New York.

[20] Ebeigbe, P.N. and Gharoro, E.P. (2007) Obstetrics Complications, Intervention Rates and Maternal Fetal Outcome in Teenage Nullipara in Benin City, Nigeria. Tropical Doctor, 37, 79-83. https://doi.org/10.1177/004947550703700206

[21] Mahararkar, S.H., Madhu, C.K. and Mule, V.D. (2008) A Comparative Study of Teenage Pregnancy. Journal of Obstetrics and Gynaecology, 28, 604-607. https://doi.org/10.1080/01443610802281831

[22] Harrison, K.A. (1985) Childbearing Health and Social Priorities. A Survey of 22,774 Consecutive Hospital Births in Zaria; Northern Nigeria. British Journal of Obstetrics and Gynaecology, 5, 23-31.

[23] Klepinger, D.H., Lundberg, S. and Plotnick, R.D. (1995) Adolescent Fertility and the Educational Attainment of Young Women. Family Planning Perspectives, 27, 23 28. https://doi.org/10.2307/2135973

[24] Astone, M.N. and Upchurch, D.M. (1994) Forming a Family, Leaving School Early and Earning a GED: A Racial and Cohort Comparison. Journal of Marriage and Family, 56, 759-771. https://doi.org/10.2307/352884

[25] Ahn, N. (1994) Teenage Childbearing and High School Completion: Accounting for Individual Heterogeneity. Family Planning Perspectives, 26, 17-21. https://doi.org/10.2307/2136091

[26] Thato, S., Rachukul, S. and Sopa Jaree, C. (2007) Obstetrics and Perinatal Outcomes of the Pregnant Adolescents: A Retrospective Study. International Journal of Nursing Studies, 44, 1158-1164. https://doi.org/10.1016/j.ijnurstu.2006.05.016

[27] Moini, A., Riazi, K. and Mehr parvar, A.H. (2002) Pregnancy and Labour Complication in Teenagers in Tehran. International Journal of Obstetrics \& Gynaecology, 78, 245-247. https://doi.org/10.1016/S0020-7292(02)00141-8

[28] Jolly, M.C., Sebire, N., Harris, J. and Robinson, S. (2000) Obstetric Risk of Pregnancy in Women Less than 18 Years Old. Obstetrics \& Gynecology, 96, 962-966. https://doi.org/10.1097/00006250-200012000-00018

[29] Osbourne, G.K. and Howat, R.C.C. (1981) The Obstetric Outcome of Teenage Pregnancy. British Journal of Obstetrics and Gynaecology, 88, 251-321. https://doi.org/10.1111/j.1471-0528.1981.tb00971.x

[30] Bacc, A., Manhica, G.M., Machungo, F., Bugalho, A. and Cuttini, M. (1993) Outcome of Teenage Pregnancy in Maputo, Mozambique. International Journal of $G y$ necology \& Obstetrics, 40, 19-23. https://doi.org/10.1016/0020-7292(93)90767-Q

[31] Mahfouz, A.A., el-Said, M.M., al-Erian, R.A. and Hamid, A.M. (1995) Teenage Pregnancy: Are Teenagers a High Risk Group? European Journal of Obstetrics \& Gynecology and Reproductive Biology, 59, 17-20. https://doi.org/10.1016/0028-2243(94)02012-4

[32] Mukhopadhyay, P., Chaudhuri, R.N. and Paul, B. (2010) Hospital-Based Perinatal Outcome and Complications in Teenage Pregnancy in India. Journal of Health, Population and Nutrition, 5, 494-500. https://doi.org/10.3329/jhpn.v28i5.6158

[33] Kushwaha, K.P., Rai, A.K., Rathi, A.K., Singh, Y.D. and Sirohi, R. (1993) Pregnancies in Adolescents: Fetal, Neonatal and Maternal Outcome. Indian Pediatrics, 30, 
501-505

[34] Mehra, S. and Agrawal, D. (2004) Adolescent Health Determinants for Pregnancy and Child Health Outcomes among the Urban Poor. Indian Pediatrics, 41, 137-145.

[35] Iklaki, C.U., Inaku, J.U., Ekabua, J.E., Ekanem, E.I. and Udo, A.E. (2012) Perinatal Outcome in Unbooked Teenage Pregnancies in the University of Calabar Teaching Hospital, Calabar, Nigeria. ISRN Obstetrics and Gynecology, 2012, Article ID: 246983. https://doi.org/10.5402/2012/246983 